ISSN: 2238-8052

\title{
A EDUCAÇÃO AMBIENTAL NO ENSINO DE GEOGRAFIA: UMA PROPOSTA DE ATIVIDADE PEDAGÓGICA A PARTIR DOS IMPACTOS AMBIENTAIS DA PRODUÇÃO DE CERÂMICAS VERMELHAS
}

\author{
ENVIRONMENTAL EDUCATION IN GEOGRAPHY TEACHING: A PROPOSED PEDAGOGICAL \\ ACTIVITY FROM THE ENVIRONMENTAL IMPACTS OF RED CERAMIC PRODUCTION
}

\author{
Antônio Hélton Vasconcelos dos SANTOS ${ }^{1}$ \\ Marcela de Melo Soares SALES ${ }^{2}$ \\ Valéria Sandra de Oliveira COSTA ${ }^{3}$
}

Palavras-chave: Didática, Impactos Ambientais, Conhecimento Geográfico, Indústria de Cerâmicas Vermelhas.

\section{R E S U M O}

0 presente artigo visa propor um modelo de atividade didática que insira a Educação Ambiental no ensino de Geografia, a partir dos impactos ambientais causados pelas indústrias de cerâmicas vermelhas no município de Paudalho-PE. Para tanto, foi efetuado um levantamento de literatura e pesquisa documental nos Parâmetros Curriculares Nacionais, na Política Nacional de Educação Ambiental, bem como em escritos de especialistas nesse campo de pesquisa, a fim de entender a relação entre a Educação Ambiental e os componentes curriculares da Geografia. Em seguida, questionários fechados foram elaborados e distribuídos entre os educandos para verificar sua compreensão a respeito dos impactos ambientais provenientes das atividades industriais em apreço, juntamente com as práticas educativas desenvolvidas no âmbito escolar. Percebe-se que antes da execução da atividade os estudantes não possuíam uma compreensão sistêmica da Educação Ambiental, assim como dos problemas ambientais que afetam o município. Pôde-se depreender que as atividades pedagógicas desenvolvidas favoreceram o raciocínio geográfico dos discentes, além do apuramento da percepção dos problemas ambientais e das reflexões a respeito da relação sociedade-natureza, sendo uma importante ferramenta para efetivação da Educação Ambiental formal.

Keywords: Didactics, Environmental Impacts, Geographical Knowledge, Pottery.

\section{A B S T R A C T}

The present article aims to propose a didactic activity model that inserts Environmental Education in Geography teaching, based on the environmental impacts caused by the red ceramic industries in the municipality of Paudalho-PE. For that, a literature survey and documentary research were carried out in the National Curriculum Parameters, in the National Policy of Environmental Education, as well as in writings of specialists in this field of research, in order to understand the relationship between Environmental Education and the curriculum components of Geography. Then, closed questionnaires were prepared and distributed among the students to verify their understanding of the environmental impacts witch regard to the industrial activities under consideration,

\footnotetext{
${ }^{1}$ Mestre e Doutorando em Desenvolvimento e Meio Ambiente do Prodema-UFPE. E-mail: heltomvasconcelospenet@hotmail.com.

2 Doutoranda em Desenvolvimento e Meio Ambiente do Prodema-UFPE e Mestra em Políticas Públicas do MPPP/UFPE. Email: marcelasmm@gmail.com.

3 Profa. Dra. Colaboradora da rede Prodema - UFPE e PNDP. E-mail: costavso@yahoo.com.br.
} 
together with the educational practices developed in the school context. It is noticed that before the execution of the activity students did not possess a systemic understanding of the Environmental Education, as well as of the environmental problems that affect the municipality. It could be concluded that the pedagogical activities developed favored the students' geographical reasoning, as well as the assessment of the environmental problems and the reflections regarding the society-nature relationship, being an important tool for the implementation of formal Environmental Education.

\section{NOTAS INTRODUTÓRIAS}

Tratar da construção de conhecimento com os discentes envolve mais que teoria, pauta-se por uma estreita relação entre o meio físico e social. Nesse sentido, cabe à comunidade escolar proporcionar uma experiência efetiva recorrendo a atividades que articulem o cotidiano dos alunos às concepções teóricas do entorno. A necessidade de estudo e compreensão do mundo está diretamente associada ao conceito de Geografia, tornando possível a aplicação de experiências educacionais concretas com lugares do cotidiano dos alunos, como postula Santos (1996, p. 45) ao afirmar que:

Cada localização é, pois, um momento do imenso movimento do mundo, apreendido em um ponto geográfico, um lugar, por isso mesmo, cada lugar está sempre mudando de significação, graças ao movimento social: a cada instante as frações da sociedade que lhe cabem não são mais as mesmas.

Por conseguinte, a Educação Ambiental (EA) aliada à Geografia possibilitam acompanhar as alterações do meio, pois consideram que o cotidiano está estruturado por intermédio do ser social em diferentes dimensões: "dimensão da corporeidade, dimensão da individualidade e a dimensão da sociabilidade compondo o espaço e fornecendo a esta significação determinante para a formação social" (SANTOS, 1996, p. 60).

Sendo o espaço permeado por diversas concepções (ambientais, geográficas e sociológicas), a prática da EA demanda uma abordagem interdisciplinar, suscitando a esperada interação entre o cotidiano do educando e as temáticas ambientais de forma simples, de viabilizar ações que minimizem ou previnam os problemas identificados. A prática docente do ensino de geografia insere a EA, pois ela está sob a ótica da espacialidade, ou seja, do mundo; bem como a atuação do ser humano como principal causador de interferência na dinâmica deste ambiente.

Cabe destacar que os temas ambientais são factíveis de ações pedagógicas interdisciplinares, posto que possui, em sua gênese, um caráter conceitual abrangente. A própria concepção de ambiente apresentada por Leff (2001) traz uma visão da relação complexa e sinérgica da realidade cujas conexões de ordem física, biológica, termodinâmica, econômica, política e cultural, desmistificam a 
percepção de ambiente como formado exclusivamente pelos sistemas ecológicos. Logo, o habitat é todo o espaço vivido e constantemente modificado pelo homem.

Nessa perspectiva, Morin (2001) considera o pensamento complexo essencial para a compreensão da relação antrópica com o espaço, pois ao utilizar a razão aberta consegue articular as diversas polaridades e os elementos contraditórios existentes, buscando identificar, sob a ótica da interdisciplinaridade, os fenômenos que ocorrem em diferentes glebas.

Ademais, a ciência geográfica vem adaptando suas teorias fundamentais acerca da relação do homem com a natureza, e dessa maneira, reformulando suas concepções, trazendo-o para o centro da discussão, uma vez que já demonstrava sua capacidade de interferência no meio ambiente (MONTEIRO, 2015). A EA propicia aos estudantes uma percepção contextualizada, em suas escalas local, regional e global, segundo Dias (2002, p. 221):

A Educação Ambiental (EA) por ser renovadora, induzir novas formas de conduta nos
indivíduos e na sociedade, por lidar com as realidades locais, e por adotar uma
abordagem que considera todos os aspectos que compõem a questão ambiental -
aspectos sociais, políticos, econômicos, culturais, étnicos, ecológicos, científicos e
tecnológicos - por ser catalizadora de uma educação para o exercício pleno e
responsável da cidadania.

Essas observações apontam a necessidade dos docentes desenvolverem aulas que viabilizem a introdução da EA nos componentes curriculares de Geografia, possibilitando uma formação crítica que tornem os estudantes capazes de diagnosticar as degradações provocadas no meio ambiente.

Para avaliar os efeitos transformadores da EA, este estudo considerou os impactos ambientais causados pelas olarias do Município de Paudalho-PE. Este segmento industrial tem significativa presença na localidade, totalizando cerca de 39 empresas que vêm acarretando danos aos sistemas ecológicos, e consequentemente, prejudicando a qualidade de vida dos munícipes com a constante poluição atmosférica, desmatamentos, contaminação dos recursos hídricos, exploração do trabalho, erosão e degeneração do solo, entre outros (HOLANDA, 2011; SANTOS, 2018).

Diante do exposto, o objetivo deste trabalho foi elaborar um modelo de atividade que insira a Educação Ambiental no ensino de Geografia, a partir dos impactos ambientais causados pelas indústrias de cerâmicas vermelhas. Tal proposta pedagógica fundamenta-se na necessidade dos discentes refletirem criticamente sobre as intervenções produzidas no espaço pela produção de cerâmicas vermelhas, e assumirem seu papel de agentes de transformação da realidade, cobrando do poder público que realizem ações para mitigar os impactos dessa atividade econômica, como a adoção de práticas sustentáveis voltadas para o desenvolvimento local. 


\section{MATERIAL E MÉTODOS}

\subsection{Delimitação e caracterização do objeto da pesquisa}

A pesquisa foi realizada com $40^{4}$ alunos do 9a ano do ensino fundamental na Escola Estadual de Referência em Ensino Médio Confederação do Equador, localizada no município de Paudalho, pertencente à mesorregião da zona da mata norte pernambucana (Figura 1). Nele são desenvolvidas as seguintes atividades econômicas: turismo religioso de São Severino dos Ramos, monocultura da canade-açúcar, hortifrutigranjeiros e a produção de cerâmicas vermelhas (SANTOS; CASTILHO; COSTA, 2018).

Vale salientar que essa instituição situa-se no bairro Alto Dois Irmãos, comunidade que apresenta sérios problemas sociais e ambientais, seja pela criminalidade ou ausência de infraestrutura, como: saneamento básico, pavimentação nas ruas e assistência médica.

Figura 1. Mapa de localização do Município de Paudalho Pernambuco.

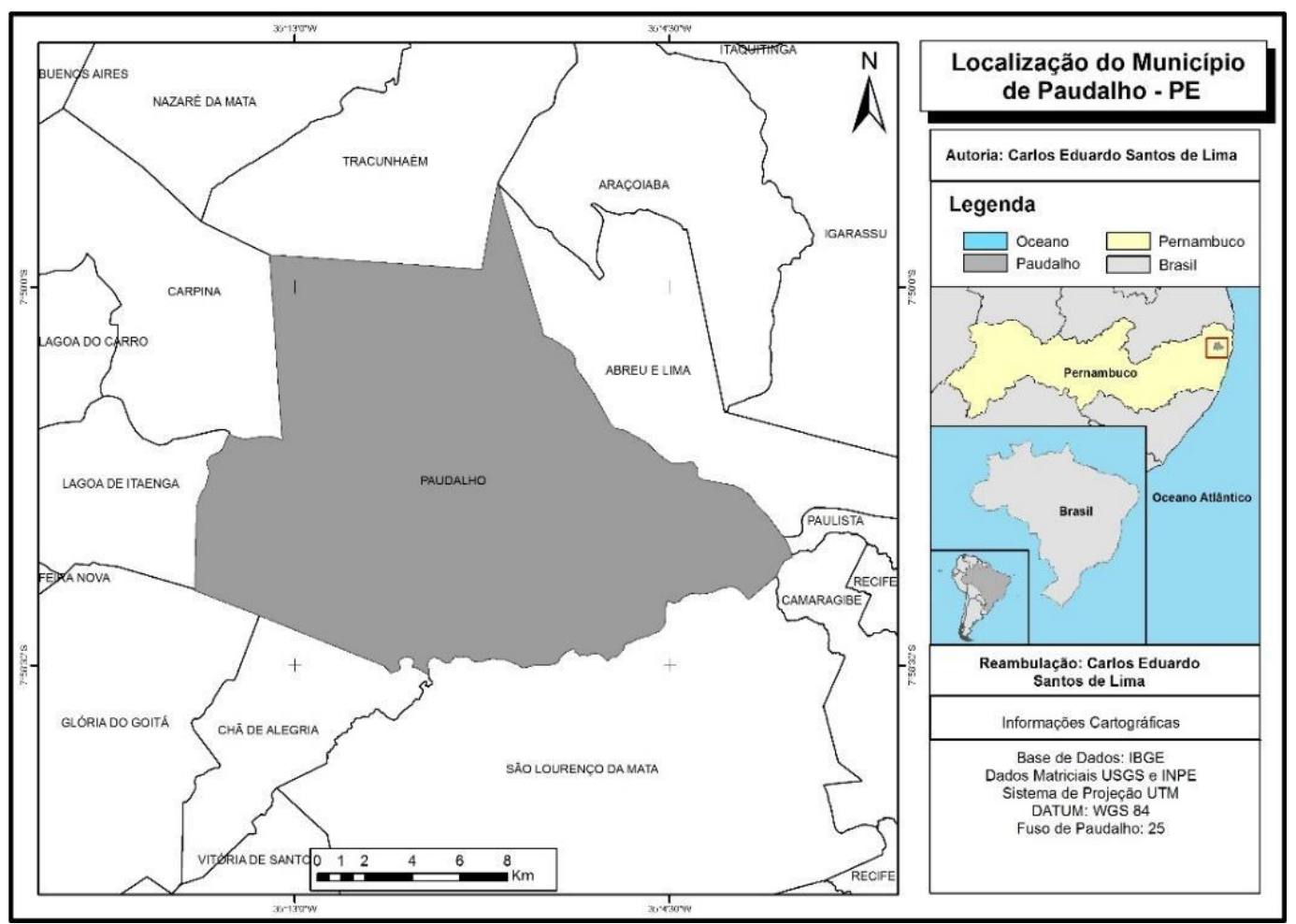

Fonte: IBGE (2016) adaptado por Antônio Hélton Vasconcelos dos Santos (2019).

\footnotetext{
${ }^{4}$ A amostra selecionada para responder os questionários designa $95 \%$ da turma objeto desta pesquisa. 0 critério de inclusão dos estudantes deu-se a partir da frequência de sua participação nas etapas das atividades propostas.
} 
Tal instituição comporta 320 estudantes distribuídos nos três turnos. Possui modalidade integral no médio, semi-integral no 9o ano do fundamental e Educação de Jovens e Adultos (EJA). Sendo também polo da educação a distância do Instituto Federal de Pernambuco (IFPE), da Universidade Federal Rural de Pernambuco (UFRPE) e dos cursos técnicos ofertados pela Secretaria de Educação do Estado. Por conta desta vasta oferta de modalidades de ensino, seus educandos advêm de diferentes bairros do município.

\subsection{Métodos e técnicas}

Para entender a relação entre a EA e o ensino de Geografia, a fim de realizar o planejamento das atividades, foi realizada pesquisa bibliográfica e documental com os principais teóricos, leis e documentos que mostram ações educativas práticas que viabilizem sua interação. Dessa forma, obteve-se uma análise apurada dos Parâmetros Curriculares Nacionais de Geografia e Meio Ambiente, ambos associados à Política Nacional de Educação Ambiental (PNEA) e aos conteúdos programáticos do ano em curso, incluindo uma avaliação do projeto político pedagógico da unidade de ensino.

Em seguida, com o intuito de verificar a compreensão dos alunos sobre os impactos ambientais provenientes das atividades industriais em análise, juntamente com as práticas educativas desenvolvidas no âmbito escolar, foram produzidos e distribuídos aleatoriamente 40 questionários fechados para os educandos antes e depois da realização das atividades.

Para a efetivação da atividade pedagógica proposta realizou-se estudo com os estudantes abordando as ações empreendidas pelas olarias que resultam na exploração indiscriminada dos recursos naturais, aulas expositivas antes e depois da excursão e por fim, após debates e visando verificar o grau de absorção dos conteúdos explanados, foram produzidas maquetes, mapas temáticos e cartazes para que os alunos envolvidos apresentassem os resultados para a comunidade escolar. Esta pesquisa teve abordagem qualitativa, segundo Marconi e Lakatos (2011) é o método capaz de captar a subjetividade dos fenômenos, compreendendo as particularidades do objeto de análise, e pode ser associado ao uso de dados estatísticos quando necessário.

\section{A EDUCAÇÃO AMBIENTAL NO ENSINO DE GEOGRAFIA}

Em 27 abril de 1999 foi promulgada a Lei no 9.795 que instituiu a Política Nacional de Educação Ambiental (PNEA). Esse dispositivo legal é consequência da problemática ambiental e da urgência da sensibilização pública para a responsabilidade socioambiental, visando à construção de competências, habilidades, atitudes e valores sociais dos indivíduos e da coletividade. 
A PNEA (BRASIL, 1999), estabelece no Artigo 2º que: “A educação ambiental é um componente essencial e permanente da educação nacional, devendo estar presente de forma articulada em todos os níveis e modalidades do processo educativo, em caráter formal e não-formal”. Fica evidente a transversalidade da educação ambiental no processo formativo e informativo, seja nas instituições educacionais (educação formal) ou nas relações sociais cotidianas (educação informal). No âmbito escolar, a EA não deverá ser ofertada como disciplina própria, mas integrada aos componentes curriculares, conforme explicitado abaixo:

Art. 10. A educação ambiental será desenvolvida como uma prática educativa integrada, contínua e permanente em todos os níveis e modalidades do ensino formal. $\S 1$ 1ํ A educação ambiental não deve ser implantada como disciplina específica no currículo de ensino.

$\S 2^{\text {o }}$ Nos cursos de pós-graduação, extensão e nas áreas voltadas ao aspecto metodológico da educação ambiental, quando se fizer necessário, é facultada a criação de disciplina específica.

§ 3o Nos cursos de formação e especialização técnico-profissional, em todos os níveis, deve ser incorporado conteúdo que trate da ética ambiental das atividades profissionais a serem desenvolvidas. (BRASIL, 1999).

Por conseguinte, suas temáticas transversais permeiam toda a prática educativa, exigindo um trabalho sistemático, contínuo, abrangente e integrado. No decorrer de todo processo de inserção da EA, os conteúdos e objetivos devem compor diferentes momentos de cada uma das disciplinas.

É importante ressaltar que os discursos e documentos elaborados pelos órgãos do sistema de educação brasileiro, do século XX, incentivaram a interdisciplinaridade e renovação pedagógica nas práticas escolares, sendo uma forma do Ministério da Educação (MEC), articular as disciplinas e debater temas relevantes à formação crítica da sociedade, como: os Parâmetros Curriculares Nacionais de Meio Ambiente, os quais dispõem sobre a transversalidade da EA:

De modo geral, o trabalho com esse tema transversal pode, dependendo de como é tratado, se constituir num espaço revigorador da vida escolar, da prática pedagógica. Ele pode reavivar o debate entre alunos de várias idades e classes, entre toda a comunidade escolar, entre escola e bairro e ainda entre instâncias maiores da administração pública. (BRASIL, 1997).

A EA não poderá ser tratada de qualquer maneira, atribuindo-se princípios básicos para plenitude de sua aplicação:

Art. 4o São princípios básicos da educação ambiental:

I - o enfoque humanista, holístico, democrático e participativo;

II - a concepção do meio ambiente em sua totalidade, considerando a interdependência entre o meio natural, o socioeconômico e o cultural, sob o enfoque da sustentabilidade;

III - o pluralismo de ideias e concepções pedagógicas, na perspectiva da inter, multi e transdisciplinaridade;

IV - a vinculação entre a ética, a educação, o trabalho e as práticas sociais;

$\mathrm{V}$ - a garantia de continuidade e permanência do processo educativo;

VI - a permanente avaliação crítica do processo educativo;

VII - a abordagem articulada das questões ambientais locais, regionais, nacionais e globais; 
VIII - o reconhecimento e o respeito à pluralidade e à diversidade individual e cultural. (BRASIL, 1999).

Para trabalhar temas transversais é fundamental que estes se combinem com as concepções teóricas e metodológicas das disciplinas a serem contextualizadas, cabendo ao educador construir essas interfaces. No caso da Geografia que tem seu foco no espaço, tanto na formação socioespacial, como nas territorialidades e temporalidades do mundo, é mais fácil integrar as questões ambientais descritas nos Parâmetros Curriculares Nacionais de Geografia:

Como o objeto de estudo da Geografia, no entanto, refere-se às interações entre a sociedade e a natureza, um grande leque de temáticas de meio ambiente está necessariamente dentro do seu estudo. Pode-se dizer que quase todos os conteúdos previstos no rol do documento de Meio Ambiente podem ser abordados pelo olhar da Geografia. (BRASIL, 1998).

Sendo assim, tornam-se evidentes as possibilidades de articulação entre a Geografia e a prática da EA, pois estão ligadas de forma harmoniosa, considerando os procedimentos, conceitos básicos e as especialidades, que fundamentam essa ciência. Além disso, existem várias abordagens, curriculares ou metodológicas, para contemplar significados diferentes da EA no ensino de Geografia. Deste modo, faz-se imprescindível que os professores desta ciência de síntese foquem a compreensão dos valores e conceitos envolvidos no processo educativo, pois suscita escolhas adequadas à realidade vivenciada pela comunidade escolar.

De acordo com Loureiro (2015), quando a EA assume uma perspectiva de prática pedagógica crítica, baseando-se em uma educação transformadora, ética e responsável, os preceitos do educador Paulo Freire são evidenciados, assim como o processo de ensino-aprendizagem da pedagogia histórico-crítica de Saviani.

Cavalcanti (2002) afirma que as propostas de atividades educativas no ensino de Geografia sugerem a contextualização dos conteúdos programáticos juntamente com os conceitos geográficos que são: paisagem, lugar, território, região e espaço, considerando os aspectos físicos e naturais dos territórios vividos da comunidade escolar. Marcomin e Sato (2016) concordam com esse pensamento e atentam para a relevância do uso desses eixos temáticos na percepção ambiental, fortalecendo a EA, seja no âmbito formal ou informal.

Torna-se oportuno o exercício da EA não só para a Geografia, mas para as múltiplas áreas do conhecimento escolar por incentivarem os estudantes à pesquisa nas ciências ambientais. Sobre isso, Sato (2001, p. 33) indaga que:

Uma pesquisa em EA deve ter ecos, além mares, ares, terras e fogos. Tem que ser intensa em seus contrastes de formas, representações, volumes e composições. Só assim poderemos encontrar um plano dinâmico sob uma nova essência do conhecimento. Um conhecimento enraizado em sonhos, que permaneça no impulso criativo e crítico das diversas formas de existência e que, sobremaneira, consiga novas formas de ultrapassagens às violências vivenciadas pela nossa era. A busca deste desejo nos revela que não somos somente testemunhas da civilização e barbárie. A EA 
deve ter o compromisso de permitir sermos protagonistas para alcançar a utopia apaixonadamente e sempre!

Percebe-se que a EA possibilita a reflexão acerca da realidade, alçando o indivíduo ao papel de agente de transformação, ou seja, reforçando a ideia de mobilização da comunidade para lutar em prol de ações que conciliem crescimento econômico e sustentabilidade ambiental.

\section{ATIVIDADES PROPOSTAS DE INSERÇÃO DA EA NO ENSINO DE GEOGRAFIA A PARTIR DOS PROBLEMAS AMBIENTAIS PROVOCADOS POR INDÚSTRIAS DE CERÂMICAS VERMELHAS}

Para verificar a compreensão dos alunos sobre os problemas ambientais causados pelas olarias e a existência de práticas educativas de EA no ensino de Geografia foram aplicados questionários fechados para preenchimento dos estudantes. Tal averiguação foi necessária para a realização do estudo comparativo com os resultados adquiridos após a aplicação do modelo proposto nesta pesquisa.

Como amostra representativa da escola, 40 alunos responderam o questionário, identificando cada sujeito pelo número atribuído ao seu respectivo relatório. Considerando a EA, apenas 28 estudantes relataram que os educadores desenvolviam atividades significativas com essa temática e que estas se restringiam às disciplinas de Geografia e Ciências.

Quanto à consciência ambiental, 32 discentes informaram saber dos problemas que acometem o município, pois os conceitos básicos recebidos nas aulas permitiam um diagnóstico do local em que vivem. No entanto, os alunos não associam a degradação existente às atividades das olarias. 36 respondentes identificaram como causas prováveis: o lixo nas ruas, o lixão no entorno da escola, o esgoto doméstico despejado nos rios que cruzam o território. Ficou evidente que os estudantes apenas destacam impactos ambientais físicos, ignorando o que de fato é EA.

Confirmando essa deficiência no aprendizado, apenas 13 estudantes marcaram as alternativas provenientes da produção de cerâmicas vermelhas como: erosão, poluição atmosférica, exploração do trabalho, poeiras e fuligem. Cabe ressaltar que 17 estudantes possuem parentes trabalhando em olarias, a escola encontra-se próxima a duas grandes fábricas deste segmento e que somente cinco deles chegaram a visitar estes empreendimentos. Mesmo assim, todos os educandos acham relevante a inserção da EA no processo educativo.

Diante da realidade retratada pelos estudantes, torna-se extremamente importante o desenvolvimento de práticas educativas na Geografia que visem à inserção da EA interdisciplinarmente, propiciando uma ampla reflexão da relação sociedade-natureza, conjuntamente com os impactos ambientais provenientes das indústrias de cerâmicas vermelhas. E desenvolver atividades práticas atreladas aos conhecimentos teóricos abordados em sala proporcionará aos 
estudantes uma análise crítica sobre o que é, e como se apresenta o espaço geográfico no qual estão inseridos, e de que maneira a intervenção humana pode alterar positiva ou negativamente o ambiente, visto que, "o espaço geográfico seria, então, a paisagem animada pela sociedade, a materialização da relação sociedade-natureza." (SENE, 2007, p. 120).

Cabe aos docentes a produção de recursos didáticos que motivem os educandos, aproximando o conhecimento da sua realidade. Para que isso seja possível o professor necessita traçar estratégias que reitere o papel dos territórios existenciais dos alunos nas práticas educativas, o que proporcionará o estreitamento da relação entre teoria e prática de modo significativo e inclusive quebrando paradigmas existentes, percebe-se tal reverberação nas obras dos notáveis Paulo Freire, Lana Cavalcanti, Dermeval Saviani entre outros educadores que se preocupam com a formação para a cidadania.

O ensino de Geografia não é estático traz sempre inovações que buscam contextualizar a teoria por meio da prática pedagógica interdisciplinar, deste modo a docência não é abordada como um fato isolado, onde a única exigência seja assimilar. Como ratifica Rego (2007, p. 9):

0 ensino de geografia não significa meramente a exposição de um programa de conteúdos, supondo como invariavelmente já estabelecidos, acompanhada pela avaliação de sua assimilação por parte dos alunos. A distância imensa fica completa se a geografia educativa significar a possibilidade de transformar temas da vida em veículos para a compreensão do mundo, entendido não como conjunto de coisas, mas como obra de criadores - sendo a compreensão sobre os criadores parte indelegável da compreensão sobre a construção contínua da obra.

Considerando a possibilidade de contextualizar a construção do saber dentro do espaço geográfico, possibilitando aos sujeitos pesquisados associar os conhecimentos das distintas disciplinas com a problemática ambiental das olarias, criou-se um planejamento de aula de Geografia que abrange os conteúdos, neste caso do 9a ano - ensino fundamental II, abordando as seguintes temáticas: a natureza é transformada em produto pelo homem; os setores de produção; a sociedade de consumo e desperdício; indústria, sociedade e espaço; e, por fim, os problemas ambientais urbanos.

Para melhor articulação entre território vivido e conhecimento, faz-se necessário aplicar um estudo do meio, onde os alunos poderão presenciar a situação problema, observar e analisar de forma holística as realidades aparentes ou não, facilitando a compreensão do espaço geográfico e dos seus agentes formuladores, concatenando às diretrizes legais dos parâmetros curriculares. 0 estudo do meio é uma ferramenta para o ensino da Geografia, devendo ser trabalhado da seguinte forma: antes da excursão o professor deve preparar uma aula introdutória contendo os conceitos que serão utilizados durante a aula de campo, bem como um roteiro com os locais essenciais ao objetivo da atividade.

Essa estratégia de ensino permite aos estudantes ressignificar sua relação com a natureza e modifica um sistema tradicional de educação engessado, cuja divisão em disciplinas fragmenta a realidade e cria sujeitos incapazes de associar os conhecimentos. A análise da paisagem possibilita o 
desenvolvimento do raciocínio geográfico dos alunos, constituindo a base para ações exploratórias e descritivas dos espaços lócus para vários exercícios propostos neste artigo, além de auxiliar na compreensão e articulação dos demais conceitos da Geografia (SANTOS et al., 2017).

A Figura 2 representa o momento da excursão realizada para a olaria em que foram explicados o contexto histórico, econômico, político, social, também foram ressaltados os problemas ambientais locais e identificados seus agentes causadores. No decorrer dessa atividade pedagógica a participação dos alunos foi fundamental para relacionar os conceitos do cotidiano com os conteúdos abordados em sala de aula.

Figura 2. Registo da excursão pedagógica a olaria de Paudalho-PE.

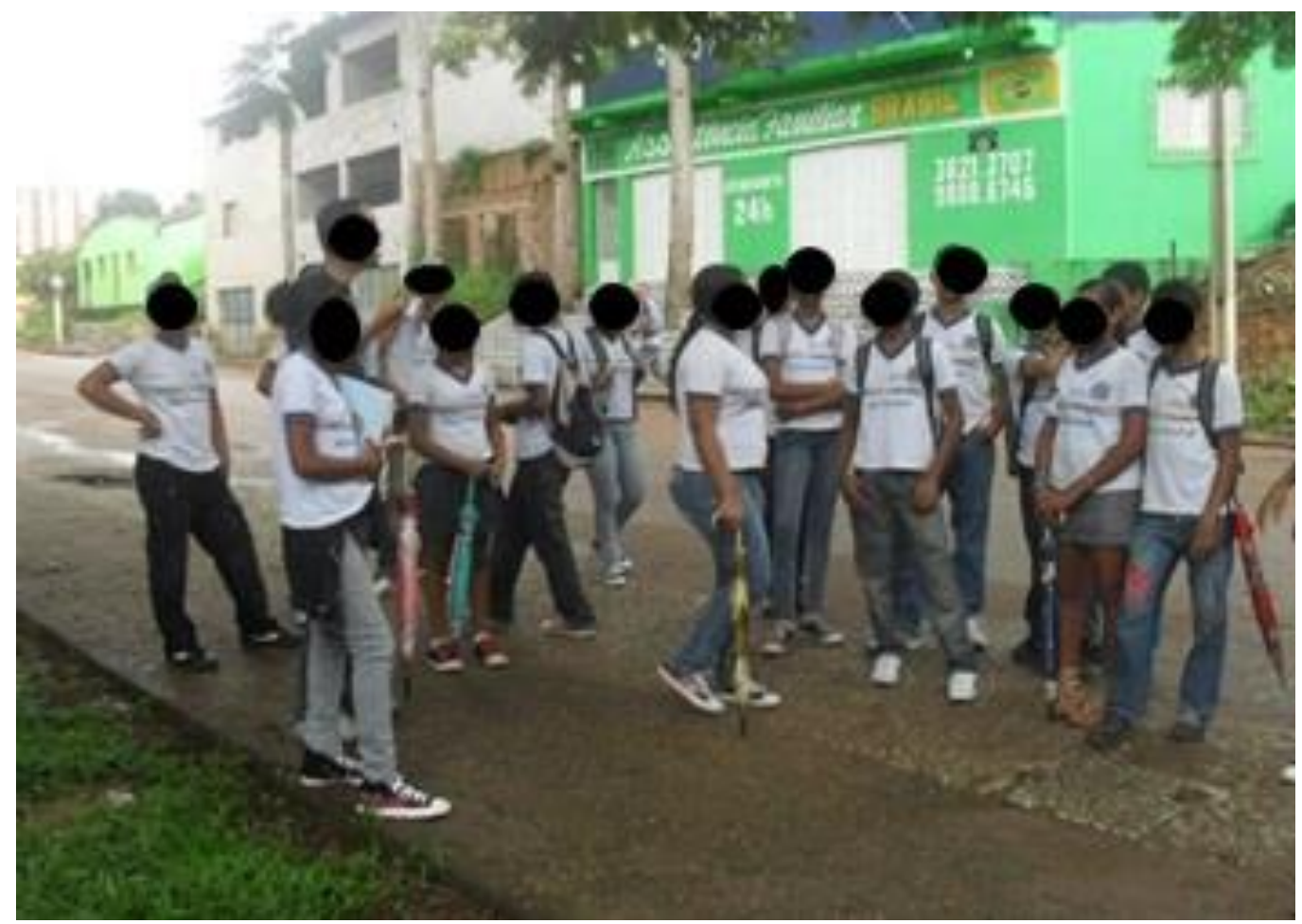

Fonte: Melo (2016a).

Os relatos individuais de cada educando, trazendo observações, algumas até desconhecidas pelo docente, promoveram a construção do conhecimento coletivo, tornando todos os partícipes da atividade sujeitos ativos do processo. Um elemento importante a ser observado é o interesse dos estudantes que participaram, evidenciados pela espontaneidade de seus questionamentos, surgindo diversos "Por quês?" revelando o quão oportuna é a conexão da teoria com a prática. Na indústria ceramista, os mesmos observaram todas as etapas da produção da cerâmica (Figura 3) e também a relação da força e divisão do trabalho. 
Figura 3. Visita à área interna de produção das cerâmicas em uma olaria de Paudalho-PE.

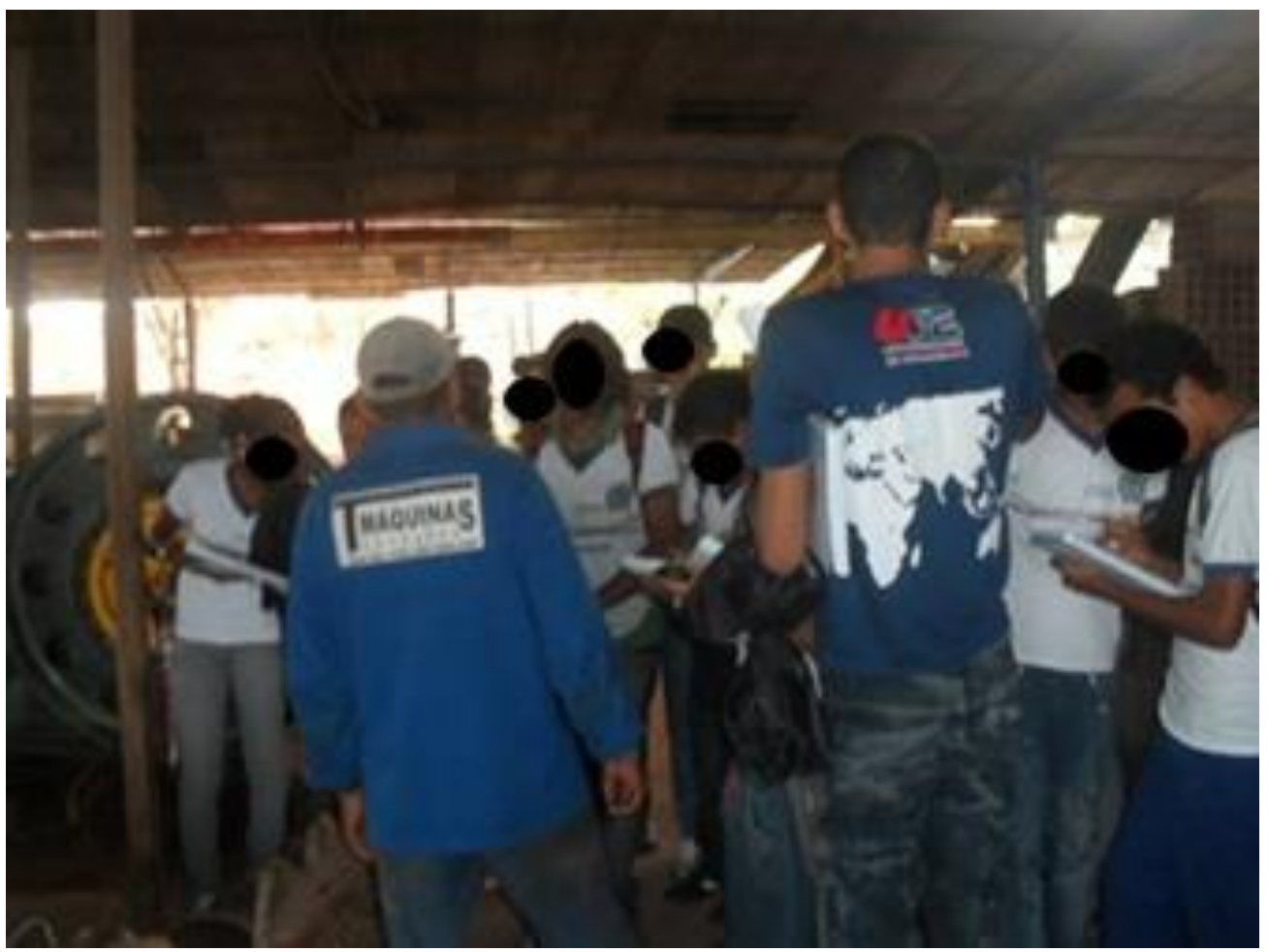

Fonte: Melo (2016b).

Na visitação da área interna, os estudantes puderam visualizar cada processo da produção e seu respectivo maquinário, racionalizando sobre a influência da máquina no mercado de trabalho, impactos negativos e positivos, como o aumento da produtividade. Essas temáticas transversais acolhem a contextualização das orientações curriculares, desenvolvendo competências e habilidades, posto que nessa vivência de campo os discentes fortaleceram as categorias dos conhecimentos atitudinais, conceituais e procedimentais, por meio da solidariedade, respeito, compromisso, oratória e capacidade de trabalho em grupo.

0 trabalho pedagógico não é um processo adaptativo dos sujeitos, mas um processo de ampliação de consciência e de emancipação que lhes permitem contemplar não apenas fragmentos para participação cultural, e sim uma base, um núcleo forte de profunda autovalorização, autoconfiança e solidariedade de grupo. Ele inclui aspectos éticos e emocionais que estão sempre presentes nas relações entre as pessoas. (DAVINI, 1995, p. 57-58).

A aula de campo proporciona ao professor maior interatividade com os alunos, promovendo uma relação amigável e confiável que afasta a visão tradicional hierarquizada em relação ao grupo. Essa aula "informal" demonstra que sua função transcende o conhecimento de sua disciplina, simbolizando uma aproximação maior com os educandos.

Após conhecer todo processo de produção e as relações de trabalho, destacam-se as problemáticas ambientais (Figura 4). Na ocasião os educandos puderam verificar os efeitos da exploração inadequada do meio ambiente, pois estas olarias utilizam os recursos naturais de forma 
desordenada, afetando o equilíbrio ecológico. Também foi discutida a influência do capitalismo e até mesmo dos hábitos corriqueiros nessa degradação, podendo, com isso, sensibilizá-los para uma mudança de comportamento.

Figura 4. Visita ao campo para verificar os impactos ambientais ocasionados pelas olarias.

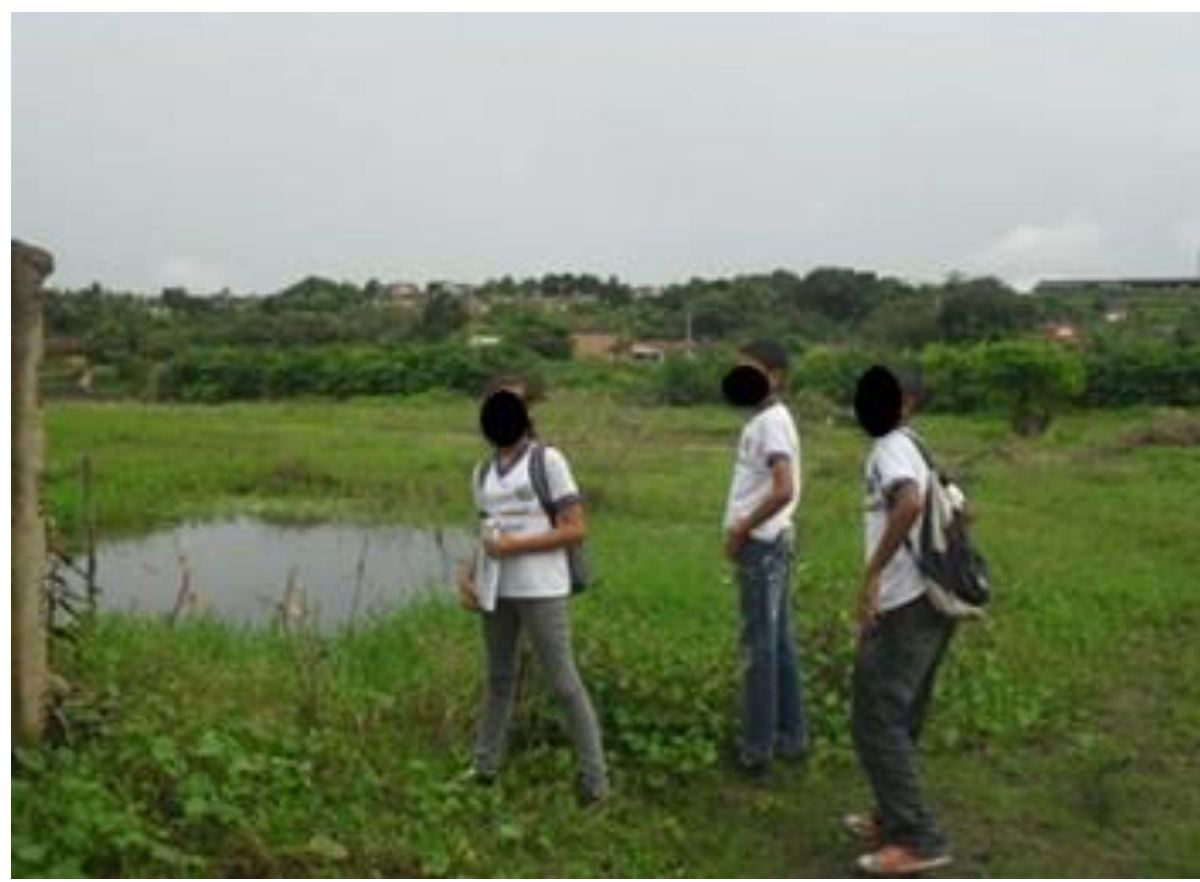

Fonte: Santos (2016).

Após o estudo de campo foi realizada uma abordagem didática do conteúdo, de forma que pudessem ser fixados todos os assuntos relacionados na excursão e evidenciados os aspectos conjunturais de cada situação observada.

É que na medida em que o testemunho não é um gesto no ar, mas uma ação um enfrentamento, com o mundo e com os homens, não é estático. É algo dinâmico que passa a fazer parte da totalidade do contexto da sociedade em que se deu. E, daí em diante, já não para. (FREIRE, 2004, p. 176).

Com este fim, a turma foi dividida em grupos ficando cada um responsável por uma temática específica e pela produção de materiais didáticos e conteúdos midiáticos, para que realizassem uma exposição na qual outras séries da mesma instituição de ensino pudessem assistir. Cabe salientar que as orientações passadas aos discentes são para relacionarem os parâmetros curriculares com os impactos ambientais vivenciados em campo. Tendo as seguintes etapas de atividades:

Primeiramente, a construção de mapas temáticos identificando cada local percorrido, visando aprimorar a noção de localização e de escala dos estudantes, como também, o georreferenciamento dos impactos ambientais, derivado da produção de cerâmicas vermelhas, conjuntamente com a elaboração de quadros explicativos das causas, agentes e consequências dos problemas observados. 
Ademais, foram desenvolvidos cartazes com fotos e imagens apresentando as etapas do processo de produção, e elaborados gráficos para ilustrar os resultados das entrevistas e questionários com os proprietários e funcionários da empresa (Figura 5A).

Logo após, foi realizada a construção da maquete do forno contínuo - usada para combustão da cerâmica vermelha - com materiais recicláveis (Figura 5B). Dado que a utilização de maquetes como ferramenta pedagógica é uma excelente opção para o auxílio na exposição e fixação de assuntos, pois demonstra como um fenômeno real pode acontecer de forma simples (SABINO; FERNANDO; SABINO, 2009).

Figura 5. Confecção de cartazes e mapas (A) e de uma maquete do forno contínuo representado o processo de produção de cerâmica vermelha.

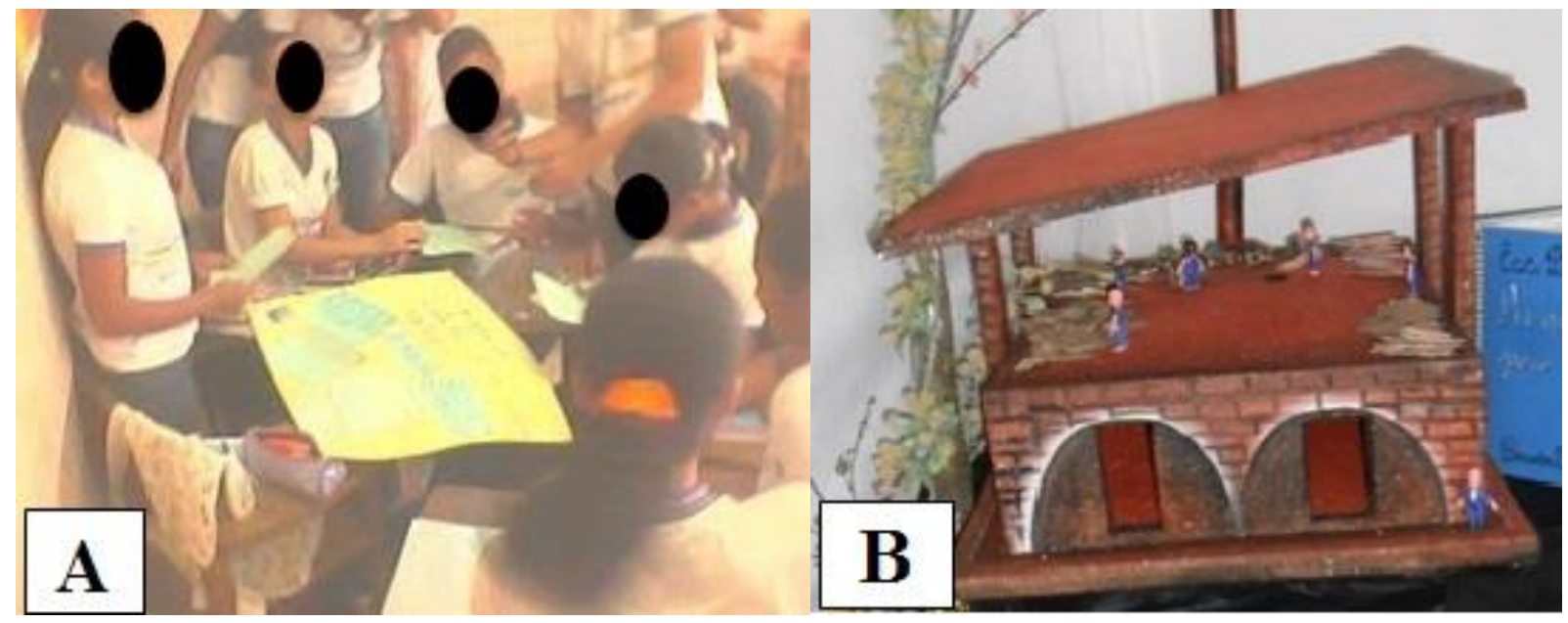

Fonte: Santos (2016).

Por fim, os grupos apresentaram para a escola todos os elementos supracitados, compartilhando o conhecimento adquirido e aprimorando competências e habilidades. Com esses procedimentos metodológicos adotados pelos professores notou-se a aplicabilidade da educação ambiental em conformidade ao ensino da Geografia, segundo Reigota (1998) a EA aponta para propostas pedagógicas centradas na conscientização, mudança de comportamento, desenvolvimento de competências, capacidade de avaliação e participação dos educandos em relação ao meio em que se vive.

\section{AVALIAÇÃO DA ATIVIDADE PROPOSTA}

Ao finalizar qualquer atividade pedagógica é indispensável sua avaliação, seja para verificar os erros cometidos durante a execução e/ou averiguar se os objetivos traçados no planejamento foram 
devidamente exequíveis. O que muitos educadores desprezam nesse processo é a percepção dos sujeitos-chave, neste caso a visão dos estudantes sobre as atividades realizadas.

Os questionários aplicados seguiram os mesmos parâmetros do apresentado quando do início da atividade proposta. Os estudantes demonstraram aprovação da metodologia e no espaço reservado às sugestões, 38 discentes solicitaram retornar à indústria e desenvolver um projeto de intervenção sobre segurança do trabalho e educação ambiental com os funcionários e proprietários das cerâmicas. Quando questionados novamente acerca dos problemas ambientais existentes no município, os 40 alunos já não apresentaram dificuldade em fazer um diagnóstico mais apurado, contemplando agentes, causas e consequências.

Como etapa preferencial, todos os alunos envolvidos destacaram o estudo do meio, através da aula de campo na indústria. Logo, pode-se depreender que a atividade atingiu os objetivos propostos, favorecendo a construção do conhecimento coletivo entre estudantes e professores. Castilho (2019) reforça a importância das práticas pedagógicas com esse fim, uma vez que fortalecem os territórios vividos dos educandos frente aos interesses globais, pois desvela a essência do aparente, suscitando discussões e, consequentemente, posicionamentos da comunidade escolar diante a problemática ora observada.

\section{CONCLUSÕES}

A Geografia como uma ciência crítica e analítica proporciona ao sujeito uma compreensão e interpretação do meio em que ele vive, contextualizando as relações políticas, sociais, culturais e ambientais. Para que isso ocorra é necessário ao professor dessa disciplina estabelecer uma metodologia que viabilize a construção do conhecimento atrelando a teoria existente nos parâmetros curriculares com as experiências vivenciadas pelos estudantes em seu cotidiano.

Considera-se, então, que a construção conjunta do conhecimento geográfico contribui para o desenvolvimento da autonomia destes sujeitos aprendizes, fazendo-os compreender os direitos, limites, e as potencialidades das ciências e das tecnologias da mesma forma como estas atuam na formação da espacialidade. Inserida nos conteúdos de Geografia, mas não só desta ciência, a Educação Ambiental pode levar os educandos a pensarem de forma conectada as alterações que ocorrem da esfera local a global, e assim visualizarem novas possibilidades de gerar desenvolvimento com sustentabilidade.

Pôde-se confirmar que, se bem construída, uma atividade pedagógica que atrele a Educação Ambiental ao ensino da Geografia, tendo com eixo os impactos ambientais, neste caso aqueles provenientes da indústria de cerâmicas vermelhas, possibilita uma mudança de comportamento dos estudantes, aumentando sua consciência ambiental e despertando o interesse por temáticas afins. 
Ademais, propiciou o aprimoramento de competências e habilidades dos discentes que passaram a atuar como agentes ativos no processo de ensino aprendizagem. Propostas metodológicas como essa estimulam a participação dos estudantes, principalmente na atualidade, em que dispositivos eletrônicos têm atraído a atenção dos mesmos na sala de aula. Outro elemento importante foi a produção e exposição dos trabalhos, porquanto o educando se sente motivado e orgulhoso do produto desenvolvido por ele.

\section{REFERÊNCIAS}

BRASIL. Presidência da República. Política Nacional de Educação Ambiental. Brasília: Presidência da República, 1999.

BRASIL. Secretaria de Educação Fundamental. Parâmetros Curriculares Nacionais: meio ambiente e saúde. Brasília: MEC/SEF, 1997.

BRASIL. Secretaria de Educação Fundamental. Parâmetros Curriculares Nacionais de Geografia. Brasília: MEC/SEF, 1998.

CASTILHO, C. J. M. Fortalecimento de territórios vividos na encruzilhada dos interesses globais e locais - atividades de comunicação em andamento. In: Cury, J. F.; MAGNANI, E.; CARVALHO, R. C. P. (org.). Ambiente e território: abordagens e transformações sociais. Londrina: Madreperóla, 2019. p. 15-32.

CAVALCANTI, L. S. Geografia e práticas de ensino. Goiânia: Alternativa, 2002.

DIAS, G. F. Pegada ecológica e sustentabilidade humana. São Paulo: Gaia, 2002.

DAVINI, M. C. La formación docente em cuestión: politica y pedagogia. Bueno Aires: Paidós, 1995.

FREIRE, P. Pedagogia do oprimido. 38. ed. São Paulo: Paz e terra, 2004.

HOLANDA, R. M. Avaliação do desperdício da argila nas indústrias da cerâmica vermelha e construção civil: estudo de caso nos municípios de Paudalho e Recife no Estado de Pernambuco. 2011. Tese (Doutorado em Recursos Naturais) - Centro de Tecnologia e Recursos Naturais, Universidade Federal de Campina Grande, Campina Grande, 2011.

IBGE. Geociências: mapas municipais. Rio de Janeiro, 2016.

LEFF. E. Saber ambiental. Petrópolis: Vozes, 2001.

LOUREIRO, C. F. B. Educação Ambiental e epistemologia crítica. Revista Eletrônica do Mestrado em Educação Ambiental, Rio Grande do Sul, v. 32, n. 2, p. 159-176, 2015.

MARCOMIN, F. E.; SATO, M. Percepção, paisagem e educação ambiental: uma investigação na região litorânea de Laguna-SC, Brasil. Educação em Revista, Belo Horizonte, vol. 32, n. 2, p. 159-186, 2016.
MARCONI, M. A; LAKATOS, E. V. Metodologia científica. 6. ed. São Paulo: Atlas, 2011.

MELO, J. T. Excursão pedagógica a olaria de Paudalho-PE. 2016a. 1 fotografia.

MELO, J. T. Visita a área interna de produção das cerâmicas. 2016b. 1 fotografia.

MONTEIRO, G. L. Educação Ambiental no ensino de Geografia: uma contribuição do PIBID para alunos do ensino fundamental. Revista Brasileira de Educação Ambiental, São Paulo, v. 10, n. 1, p. 281-290, 2015.

MORIN, E. Por uma reforma do pensamento. In: NASCIMENTO, E. P.; PENA-VEJA, A. (org.). $O$ pensar complexo: Edgar Morin e a crise da modernidade. 3. ed. Rio de Janeiro: Garamond, 2001. p. 8-21.

REGO, N. Geografia Educadora, isso serve para. In: REGO, N.; CASTROGIOVANNI, A. C.; KAERCHER, N. A. (org.). Geografia: práticas pedagógicas para o Ensino Médio. Porto Alegre: Artmed, 2007. p. 10-13.

REIGOTA, M. O que é Educação Ambiental? São Paulo: Brasiliense, 1998.

SABINO, G.; FERNANDO, C. A.; SABINO, C. V. S. Proposta de uma metodologia para o ensino da estrutura e função das proteínas na disciplina Bioquímica. Revista Brasileira de Ensino de Bioquímica e Biologia Molecular, v. 1, n. 1, p. 519, 2009.

SANTOS, A. H. V. Impactos ambientais de produção de cerâmicas vermelhas. 2018. Dissertação (Mestrado em Desenvolvimento e Meio Ambiente) - Centro de Filosofia e Ciências Humanas, Universidade Federal de Pernambuco, Recife, 2018.

SANTOS, A. H. V. Construção de cartazes, mapas e maquete do forno. 2016a. 2 fotografias.

SANTOS, A. H. V. Visita ao campo para verificar os impactos ambientais ocasionados pelas olarias. 2016b. 1 fotografia.

SANTOS, A. H. V.; CARDOSO, J. V.; MESQUITA, A. N. S.; CRUZ, R. R.; ASSIS, K. S. G. A paisagem enquanto método educativo: um olhar para o aprimoramento do raciocínio geográfico. In: 
NÓBREGA, R. S. et al. (org.). Reflexões sobre o semiárido: obra do encontro do pensamento geográfico. Ananindeua: Itacaiúnas, 2017. p. 478-483.

SANTOS, A. H. V.; CASTILHO, C. J. M.; COSTA, V. S. O. 0 desafio enfrentado pelas práticas turísticoreligiosas no Santuário de São Severino dos Ramos em Paudalho, Pernambuco. Turismo y Desarrollo, Espanha, v. 11, n. 24, p. 1-14, 2018.
SANTOS, M. Espaço e método. São Paulo: Nobel , 1996.

SATO, M. Apaixonadamente pesquisadora em Educação Ambiental. Educação: teoria e prática, São Paulo, v. 9, n.16, p. 24-35, 2001.

SENE, E. Globalização e espaço geográfico. 3. ed. São Paulo: Contexto, 2007. 